\title{
A invenção da diferença: a animalização como distinção do "eu" e do "outro" no imaginário ocidental nos séculos XVIII e XIX
}

\author{
The invention of difference: the animalization as self-other \\ distinction in the western imaginary during the XVIII and XIX \\ centuries
}

Arnaldo Lucas Pires Junior*

\begin{abstract}
Resumo: Neste artigo propomos uma discussão teórica sobre um dos expedientes mais correntes de diferenciação entre os homens, a animalização do "outro". Através da análise de relatos de viagem e de obras de história natural nos sécs. XVIII e XIX, procuraremos demonstrar como a contestação da noção de humanidade enquanto atributo estático atingiu em cheio as concepções sobre a origem dos homens e aventou a possibilidade de uma hierarquização de suas experiências no mundo. Nossos esforços nos levaram a enfrentar um curioso paradoxo: os séculos XVIII e XIX - que viram florescer os ideais igualitários das revoluções burguesas - serão, ao mesmo tempo, o período em que esses valores se confinarão a grupos cada vez menores e em que se empunhará a diferença e a servidão de alguns sob o discurso da igualdade e da liberdade de outros.
\end{abstract}

Palavras-chave: Natureza; Cultura; Raça; Civilização; Barbárie.

Abstract: In this paper, we propose a theoretical discussion about one of the most common expedients of differentiation between men, the animalization of the "other". By the analysis of travel reports and Natural History works of the eighteenth and nineteenth centuries, we seek to demonstrate how challenging the notion of humanity as static attribute had hit directly the conceptions about the origin of man and raised the possibility of a hierarchy of human experience

\footnotetext{
* Doutorando pelo Programa de Pós-graduação em História Social da Universidade Federal do Rio de Janeiro, Rio de Janeiro/RJ, Brasil. E-mail: $\underline{\text { saadlucas@gmail.com }}$
}

(c) EY Direito autoral e licença de uso: Este artigo está licenciado sob uma Licença Creative Commons. Com essa licença você pode compartilhar, adaptar, para qualquer fim, desde que atribua a autoria da obra, forneça um link para a licença, e indicar se foram feitas alterações. 
in World. Our efforts led us to face a curious paradox. The eighteenth and nineteenth centuries - who have seen flourish the egalitarian ideals of bourgeois revolutions - will be at the same time, the period in which these values be confined to smaller and smaller groups and that wield a difference and servitude of some under the discourse of equality and freedom by others.

Keywords: Nature; Culture; Race; Civilization; Barbary.

\section{As incertas fronteiras entre "cultura" e "natureza"}

É preciso que tenhamos em mente que a construção das noções de identidade e diferença é sempre um processo relacional, ou seja, pode-se afirmar sem exagero que só há identificação em conjunto a um movimento contíguo de diferenciação. Desta forma, não nos parece equivocado afiançar que a oposição entre "eu" e "outro" torna-se elemento constitutivo central dos imaginários sociais de diversos povos, adquirindo papel central na história do ocidente e na forma com a qual os povos europeus viram e lidaram com as diferenças humanas. Analisar em conjunto as diferenças entre cultura e natureza e a forma com a qual procurou-se justificar a singularidade humana no complexo dos imaginários ocidentais é fundamental para encontramos as primeiras fundações de duas das noções que estarão no centro dos debates sobre raça nos séculos XVIII e XIX, as de civilização e barbárie, voltaremos a elas em breve.

Imaginários coletivos, imaginação social e identidades construídas. Nos moveremos em torno destes conceitos que, apesar de parecerem bastante abstratos, têm real significação e influência na vida cotidiana dos homens. Afirmar que os imaginários de um povo são apenas figuras quiméricas é esquecer que os projetos de futuro, as aspirações e o medo do porvir são elementos que moldam e direcionam as ações reais dos homens no presente. É esquecer, ainda, que os homens do passado não compartilham da certeza do desenrolar dos acontecimentos, como nós, particularmente beneficiados por nossa posição de distanciamento em relação ao passado. É, por fim, negligenciar a dimensão processual da história, como reforça Thompson neste trecho de sua crítica à Althusser,

Sua noção de "níveis" percorrendo a história a diferentes velocidades e em diferentes momentos é uma ficção acadêmica, pois todas essas "instancias" e "níveis" são de fato atividades, instituições e ideias humanas. Estamos falando de homens e mulheres, em sua vida material, em suas relações determinadas, em sua experiência dessas relações, e em sua autoconsciência dessa experiência. ${ }^{1}$ 
Diferentes imaginários sociais constroem múltiplas delimitações com relação aos limites entre natureza e humanidade e a forma com a qual estas duas dimensões - caso consideradas enquanto duas dimensões separadas - se relacionam. No antigo mundo ameríndio, por exemplo, as distâncias entre homens e animais eram incertas. Não havia nenhum tipo de oposição existencial entre humanidade e animalidade, entre natureza e cultura. Os antropólogos tendem a definir as relações entre homens e animais presentes nestas sociedades através de conceitos como "animismo" e "totemismo", ou seja, um conjunto de relações que não opõe necessariamente humanos e não-humanos, fazendo com que os primeiros imputem uma interioridade idêntica à sua para os nãohumanos. ${ }^{2}$ Assim sendo, diferentes na forma, mas compreendidos como iguais em seu interior, homens e animais compartilham do estado de cultura. ${ }^{3}$

$\mathrm{O}$ leitor atento deve ter percebido a dificuldade que o posicionamento cultural do autor gera para o desenvolvimento em perspectiva deste argumento. Ao apresentar uma relação diferente entre homens e animais, os apresentamos como humanos e "não-humanos", ou seja, ao ressaltar um diferente tipo de relação entre homens e animais, nos utilizamos de uma nomenclatura que naturaliza claramente essa distinção. Eis o pesquisador preso na armadilha de seu objeto. Para nos livrarmos desta armadilha e darmos um exemplo desta outra forma de compreender a realidade - por que não uma outra ontologia? - recorreremos ao exemplo dado por Lévi-Strauss,

O homem não é o único produtor de sons musicais, ele compartilha esse privilégio com os pássaros, mas essa constatação não afeta a nossa tese, já que, à diferença da cor, que é um modo da matéria, a tonalidade musical - tanto entre os pássaros quanto entre os homens - é um modo da sociedade. O pretenso "canto" dos pássaros situa-se no limiar da linguagem, serve à expressão e à comunicação. Os sons musicais continuam, portanto, do lado da cultura. É a linha de demarcação entre natureza e a cultura que já não segue tão exatamente quanto se acreditou no passado o traçado de nenhuma das linhas que servem para distinguir a humanidade da animalidade. ${ }^{4}$

Sendo a música um construto sociocultural, como podemos explicar o canto dos pássaros sem aceitar a fluidez do limite entre cultura e natureza? Mesmo concordando que as vocalizações destes animais cumprem a "estrita" função comunicativa, afastando assim totalmente suas melodias do mundo da estética, estaremos com um grande problema em mãos. Este problema é criado pela rigidez e profundidade das clivagens criadas entre os conceitos de natureza e cultura e entre as relações entre humanidade e animalidade. Esbarramos, dessa forma, nos limites de nossas próprias concepções culturais, e nessa constatação há um interessante exercício de humildade. 
De onde surge então, na cultura ocidental, esta relação de oposição entre homem e animal? Em que momento se desenvolve esta perspectiva cultural que, mais que uma simples tendência científica, é capaz de produzir toda uma nova forma de ligação social e gerar teorias de identidade e principalmente como veremos neste artigo - de alteridade?

Desde a antiguidade até os dias atuais os animais possuem posição fundamental nos imaginários ocidentais, eles são centrais na construção relacional daquilo que podemos definir como humanidade. Cada geração cria e recria sua imagem sobre a animalidade, colocando-a como uma deficiência em relação aos critérios que definem a humanidade. Com uma boa dose de arrogância, os homens passam a medir o mundo e as coisas dentro dele a partir de critérios "humanos", assim, os homens enxergam nos animais, desprovidos dos mesmos critérios, versões "pouco desenvolvidas" de si mesmos. Eis o antropocentrismo moldando o mundo à sua imagem e semelhança. Não é fortuito que as grandes discussões presentes nestas diversas formas de notar as diferenças entre homens e animais residem, portanto, muito mais na definição dos critérios que justificariam a singularidade humana.

A raiz moderna desta perspectiva singularista deve ser procurada no século XVIII, especificamente, no naturalismo ocidental que abre de vez a porta para o antropocentrismo -sempre simbolizado no "Homem Vitruviano" de Da Vinci - que já vinha forçando sua passagem desde o século XIV. O século XVIII assistirá uma verdadeira revolução epistemológica, a revolução do esforço classificatório, sendo este movido pela crença naturalista de que a natureza se constitui de regras gerais capazes de reger toda a diversidade natural. Cabe lembrar que a lei da gravitação universal de Newton havia sido publicada, no original em latim, em 1687 e causava intenso impacto nos meios intelectuais. Impacto este que foi captado com perspicácia pelo poeta inglês Alexander Pope, que escreveu em epitáfio dirigido ao físico, "Nature and Nature's laws lay hid in night; God said, Let Newton be! and all was light".

É sob a claridade das "luzes" de Newton - confessamos nossa falta de criatividade na escolha de uma metáfora melhor para retratar o período conhecido por "século das luzes" - que homens como o Conde Leclerc de Buffon se colocarão a escrever suas "Histórias naturais". O termo não era novo, estava presente mesmo em textos antigos, como em Plínio, o velho e sua "Naturalis historia", na qual já rascunhava-se um esforço descritivo e classificatório do mundo e dos animais. ${ }^{6}$ Esse ânimo classificatório e organizatório será a força motriz de diversas publicações que partiam em busca de uma taxonomia geral do mundo, um esquadrinhamento de cada pedaço da natureza, então recortada e nomeada. Como afirma Michel Foucault,

Au XVIIIe siècle, la continuité de la nature est exigée par toute histoire naturelle, c'est-à-dire par tout effort pour instaurer dans la nature un ordre et y découvrir des 
catégories générales, qu'elles soient réelles et prescrites par des distinctions manifestes, ou commodes et simplement découpées par notre imagination. Seul le continu peut garantir que la nature se répète et que la structure, par conséquent, peut devenir caractère. ${ }^{7}$

Será em Buffon - cuja relevância constata-se quando analisada sua influência nas obras de Lamarck e Darwin - que encontraremos uma tese interessante, que assinala os limiares de separação entre homens e animais. ${ }^{8}$ Em trecho sobre os animais selvagens, escrito em 1749, Buffon delimita as fronteiras entre o homem e o animal,

L'Ame, la pensée, la parole, ne dépendent donc pas de la forme ou de l'organisation du corps ; rien ne prouve mieux que c'est un don particulier et fait à l'homme seul, puisque l'orang-outang, qui ne parle ni ne pense, a néanmoins le corps, les membres, les sens, le cerveau et la langue entièrement semblables à l'homme ; puisqu'il peut faire ou contrefaire tous les mouvements, toutes les actions humaines, et que cependant il ne fait aucun acte de l'homme. ${ }^{9}$

No caminho aberto por Buffon, os animais, ainda que possuam algumas semelhanças em relação ao homem, se reduzem a uma posição de inferioridade. Capazes de realizar as ações humanas, fisicamente construídas, eles nunca seriam capazes da consciência dessas ações, ou seja, dos atos humanos. Dessa forma, o critério final de humanidade para Buffon residiria na interioridade, na "alma, no pensamento e na palavra". Articula-se aqui uma descontinuidade das interioridades que, mesmo diante das semelhanças externas - como as ressaltadas pelo biólogo no trecho acima citado-, passará a ditar os paradigmas para interpretar, conceituar e, principalmente, classificar a diversidade das expressões culturais dos seres humanos.

Afirmar que alguém não pertence à "humanidade" era, assim, reconhecer que, mesmo diante das aparentes semelhanças físicas, o "interior", a alma, o pensamento e o intelecto desse alguém não eram idênticos aos seus. Esse tipo de argumento, aliado a uma certa visão de humanidade particularmente etnocêntrica, moldará a forma com a qual a civilização ocidental - leia-se europeia - tratará a diversidade das culturas e etnias humanas. Daí para uma concepção etapista do processo evolutivo no âmbito das culturas é um simples passo.

Antes de analisarmos estas concepções etapistas da evolução humana, que são o resultado da expansão do esforço taxonômico desenvolvido no âmbito das ciências naturais e darão origem às tão nefastas teorias raciais que atingirão em cheio os meios científicos, propomos a análise desta pequena história, 
In the year 1647, a Swedish naval lieutenant by the name of Nicolas Köping was serving aboard a Dutch East-Indiaman in the Bay of Bengal. One day the ship approached an island whose naked inhabitants, according to Köping's account, had tails like those of cats, and a similarly feline comportment. Coming alongside in their canoes, these natives - evidently bent on trade - threatened to swarm the ship and had to be frightened off with a round of cannon-shot. The ship's pilot subsequently took ashore a landing party of five of the Dutch crew, to scour the island for provisions. They never returned, and a search mounted on the following morning revealed only their bones discarded beside a still smoldering fire, and their boat systematically stripped of its iron bolts. ${ }^{10}$

O relato de Köping pode soar aos nossos olhos contemporâneos como simples delírio de um marinheiro exposto a condições bastante difíceis. Contudo, essa história ganhou alguns reforços importantes. Em obra publicada em 1760 pelo grande zoólogo sueco Carl von Linné (Linnaeus), ${ }^{11}$ a história de nosso marinheiro dá origem a uma nova espécie de macacos denominada, com uma boa dose de ironia, de Lucifer. A imagem abaixo, publicada em livro de C.E. Hoppius - um dos pupilos diretamente orientados por Linné - mostra um grupo de seres semelhantes ao ser humano com sua devida classificação, sendo o segundo, da esquerda para a direita, representação de lúcifer, classificado como "HOMO caudatus vulgo dictus". Ainda que timidamente, a representação já contém um certo tom evolucionista, afastando o "Phygmeus", primeiro desenho à direita, do "Throglodyta", última imagem à esquerda.

\section{Figura 1 - Anthropomorpha ${ }^{12}$}

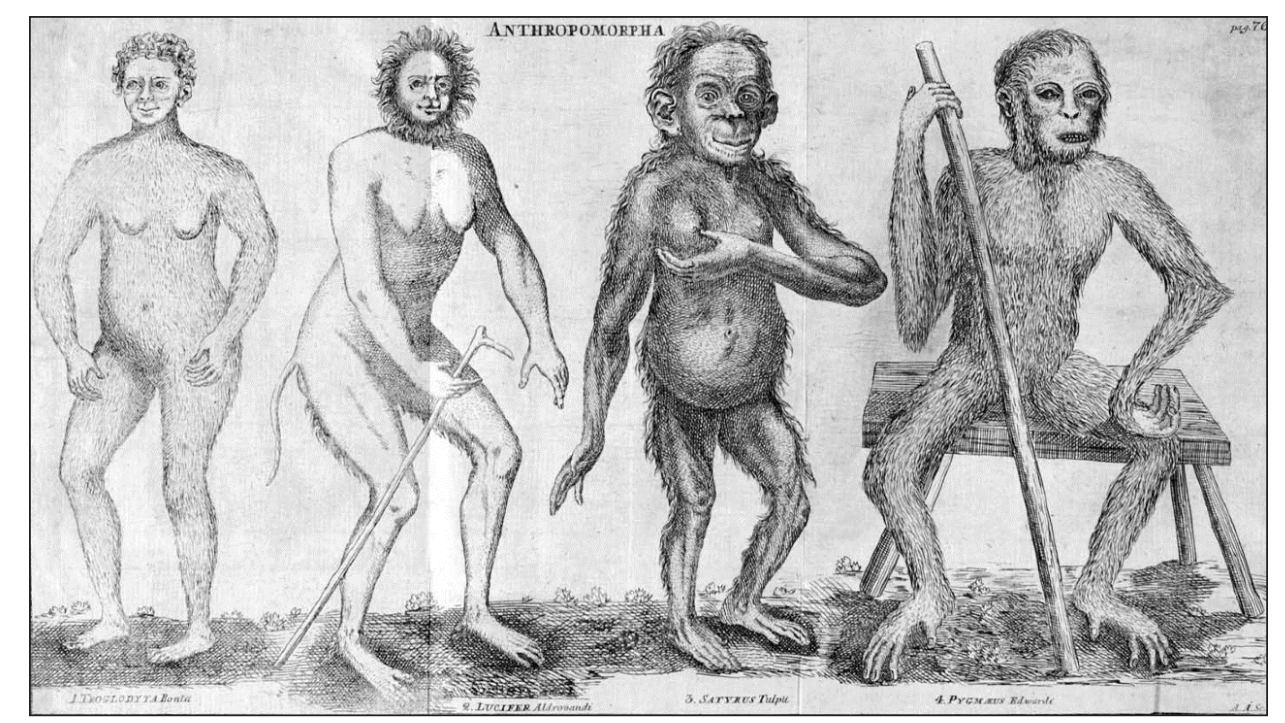


Outro autor influenciado pelo relato que acompanhamos acima foi o jurista e filósofo inglês Lord Monboddo que, em seu "Of the origins and progress of language" publicado em 1773, começa a estabelecer as continuidades e rupturas entre homens e animais. $\mathrm{O}$ argumento de Monboddo para acreditar na história do marinheiro era que equivocavam-se aqueles que acreditavam que a forma atual do homem era definitiva e irreversível, o autor inglês acreditava que a humanidade era muito mais diversa do que se conhecia até então,

I am sensible, however, that those who believe that men are, and always have been, the same in all ages and nations of the world, and such as we see them in Europe, will think this story quite incredible; but for my own part I am convinced, that we have not yet discovered all the variety of nature, not even in our own species; and the most incredible thing, in my apprehension, that could be told, even if there were no facts to contradict it, would be, that all men in the different parts of the earth were the same in size, figure, shape and color. $^{13}$

Monboddo estava errado em acreditar no relato do marinheiro, mas completamente certo em seus argumentos. Cerca de 85 anos antes da publicação de "A origem das espécies" - obra seminal de Darwin -, o Lord inglês já ensaiava os primeiros atos do que viria a ser o evolucionismo. Contudo, não é somente o pioneirismo que faz a obra do inglês interessante, Monboddo dava o primeiro golpe na noção de que a forma atual do ser humano era um atributo essencial e imutável - um golpe muito duro, digase de passagem, afinal era a imagem e semelhança de Deus que estava em jogo.

O impacto negativo que a obra de Darwin receberá quase um século depois, mostra o quão importante era a noção de humanidade enquanto atributo estático. Mostrar que a humanidade era diversa e aventar a possibilidade de que ela poderia ter se transformado ao longo do tempo não apenas atingia diversos dogmas religiosos, mas questionava a posição do homem em relação ao mundo. A ideia de uma humanidade em transformação, como resultado de um longo processo de acumulação de características, confunde os cortes dualistas que afastavam até então humanidade e animalidade. A especificidade da existência humana levava um duro golpe e não foi à toa que a própria figura de Darwin foi animalizada de diversas formas. Contudo, serão as diversas interpretações sobre as teses de Darwin que constituirão a base para a construção de teorias científicas raciais, que irão separar a humanidade em diferentes níveis de evolução e desenvolvimento social. 
Figura 2- Darwin: Essa é a forma do macaco ${ }^{14}$

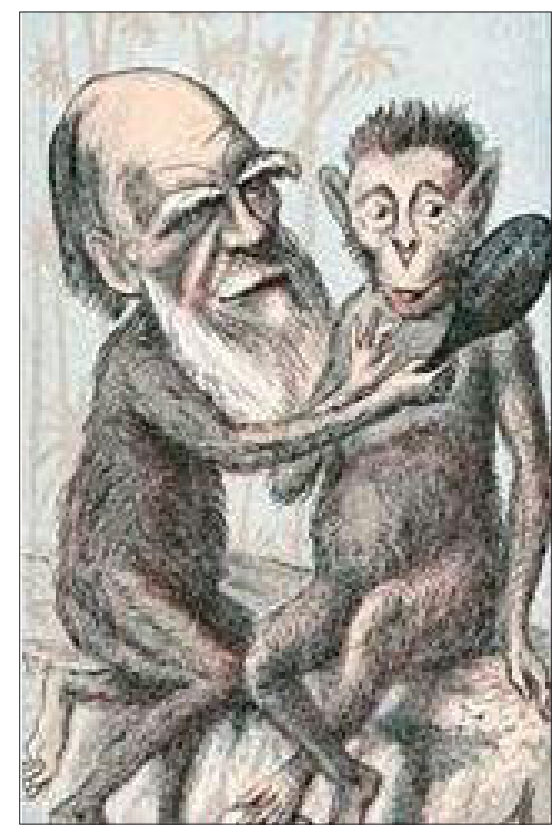

Figura 3- Darwin e a árvore das ciências ${ }^{15}$

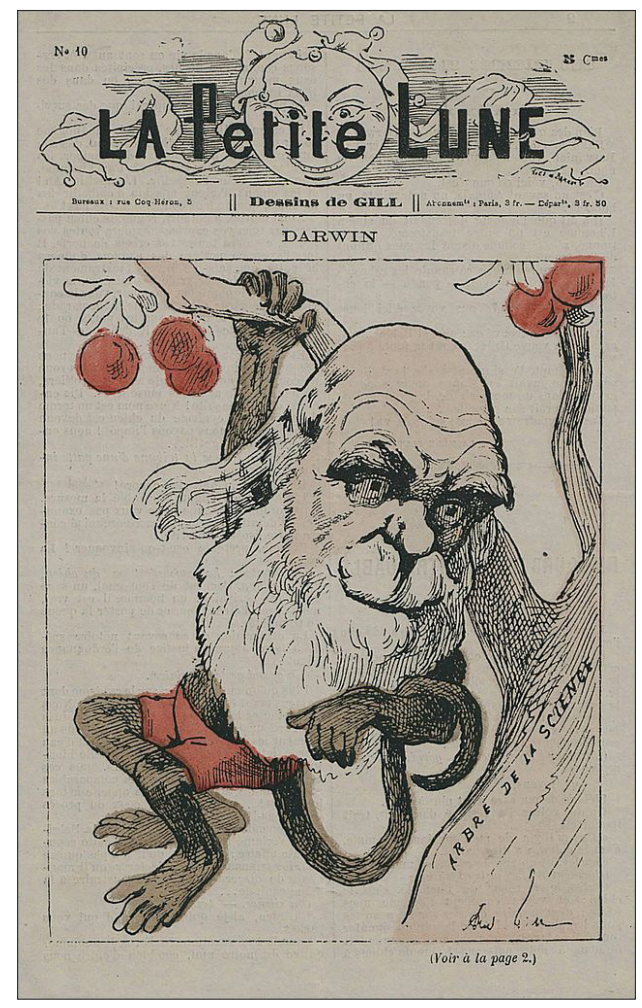




\section{O século XIX: século das teorias raciais?}

O racismo e o preconceito não são invenções da ciência, eles existiam anteriormente e se baseavam em diferentes concepções tradicionais de identidade e nas diversas formas com as quais as culturas humanas lidavam com a diferença e impunham uma noção de superioridade de determinado grupo a outro. Lynn Hunt nos mostra, por exemplo, como o processo de defesa da "naturalidade da desigualdade" entre os homens precisou se cientificizar para superar os novos discursos sobre igualdade e direitos humanos surgidos a partir do final do século XVIII. Desbotadas as justificativas da tradição principalmente após as revoluções americana e francesa - era preciso construir sob novas bases os discursos que justificavam a dominação e a submissão de determinados grupos humanos a outros. As noções de civilização e barbárie surgem como instrumentos poderosos na invenção da diferença, agora sobre novas bases. ${ }^{16}$

Foi durante o século XIX, que algumas doutrinas científicas de maior peso vieram a reforçar estas crenças de maneira inédita. De fato, a ciência de hoje olha com um certo dessabor para as concepções defendidas no passado, alguns - ainda presos na fase da negação egóica, diria Freud - procuram definilas como "pseudo-ciência". Não obstante, se considerássemos assim estas teorias, estaríamos cometendo um imenso anacronismo. A razão é simples, nenhum dos cientistas que defendiam quaisquer destas teorias imaginava que produzia uma "pseudo-ciência" - o conceito é mesmo anacrônico por si, afinal o prefixo "pseudo" se refere a uma falsa cópia diante de um padrão originalidade que, em nosso caso, é posterior. O que faziam era ciência e era sob este nome, e com todo o peso e responsabilidade advindos dele, que defendiam as ideias que veremos à frente.

Seria impossível, diante dos limites deste trabalho, definir com clareza as singularidades teóricas que subjaziam nas construções científicas sobre raça neste período. O que podemos dizer, sem o risco da generalização, é que a noção de evolução social - seja como perfectibilidade ou caractere adquirido biologicamente e, portanto, imutável - era o paradigma sobre o qual gravitavam as diferentes teorias que tratavam das noções de raça e desenvolvimento humano. Partindo desse pressuposto, nas páginas que se seguem, desenvolveremos um breve panorama, tentando apontar de que forma as teorias que tomam os meios científicos no século XIX têm ligações com o século XVIII - que já apresentamos anteriormente - e as diferentes visões que se opõem na busca pela explicação das raízes da diferença entre os homens.

Propomos, no título deste subtópico, definir o século XIX como o século das teorias raciais, contudo, os teóricos que apresentam suas teses neste período não surgem no vácuo e se referirão frequentemente aos postulados apresentados por filósofos e naturalistas no século XVIII, ainda que essa referência se dê de maneira disforme. Enquanto um grupo se aproxima da literatura humanista 
- simbolizada principalmente por Rousseau - cujo ponto central é a defesa de uma humanidade una e indivisível, outro grupo de autores se aproximará de naturalistas como Leclerc Buffon e De Pauw, com o objetivo de afirmar e justificar as diferenças entre os homens como caracteres distintivos essenciais. Estes diferentes posicionamentos não só culminarão em diversas teorias muitas vezes opostas -, como também substanciarão posições sobre a origem da diferença entre os homens e, principalmente, enfatizarão a forma com a qual a diversidade poderia ser hierarquizada.

A tradição de textos sobre as diferenças entre os homens pode ser remetida aos relatos dos contatos gerados pela expansão europeia durante as grandes navegações. Estas narrativas de viagem, misturas sensíveis de realidade e fantasia, traziam frequentemente algumas descrições sobre os hábitos e as características de homens tão diferentes, habitantes de continentes afastados e diversos em seus costumes e aparência. $\mathrm{O}$ impacto deste tipo de relato no imaginário europeu foi analisado em diversas obras historiográficas, ${ }^{17}$ como nos mostra Mello e Souza,

A descoberta da América talvez tenha sido o feito mais espantoso da história dos homens: abria as portas de um novo tempo, diferente de todos os outros - a nenhum semelhante, dizia Las Casas -, somava às já conhecidas África e Ásia uma nova porção do globo, conferia aos homens a totalidade de que eram parte. [...] Todo um universo imaginário acoplava-se ao novo fato, sendo, simultaneamente, fecundado por ele: os olhos europeus procuravam a confirmação do que já sabiam, relutantes ante ao reconhecimento do outro. Numa época em que ouvir valia mais do que ver, os olhos enxergavam primeiro o que se ouvira dizer; tudo quanto se via era filtrado pelos relatos de viagens fantásticas, de terras longínquas de homens monstruosos que habitavam os confins do mundo desconhecido. ${ }^{18}$

Contudo, apesar desta tradição de textos, será durante o século XVIII que esse "outro", o ser estranho dos relatos de viagens fantásticas, passará a ser chamado e compreendido como "primitivo" - noção entendida como "primeiro", ou seja, estágio original do desenvolvimento humano. Como ressalta Clastres,

No entanto, é uma inovação desse século [XVIII] o pensar os povos selvagens precisamente como povos primitivos. Primitivos, isto é, primeiros: no começo de uma história que é a do gênero humano. [...] Permanece a novidade de uma teoria do homem, científica e não mais religiosa 
ou metafísica (como nos séculos precedentes), e que via transformar radicalmente (quer se esteja de acordo ou não com Buffon) o modo de pensar a diversidade das sociedades. As duas ideias, a de um estado primeiro do homem e a de uma história natural da espécie, são correlatas e implicam uma terceira: que este estado primitivo é um estado de natureza. ${ }^{19}$

Elevados agora ao papel de preâmbulo do gênero humano, os homens americanos passam a se tornar objeto fundamental de uma percepção que concebia, pela primeira vez, a humanidade como espécie. Surgia, igualmente, uma concepção de homem que elegia um único caminho evolutivo e que distanciava os homens civilizados dos selvagens, ou melhor dizendo, dos "bons selvagens".

Nossa frase anterior contém, propositalmente, um conceito-chave, uma daquelas noções que ganham significados tão intrínsecos a ponto de que sua simples enunciação basta para ligarmos um conjunto de ideias à atuação de um pensador. Como o leitor sagaz já deve estar suspeitando, estamos nos referindo ao filósofo genebrino Jean Jacques Rousseau e ao papel que a noção de "bom selvagem" tem em sua obra. O "bom selvagem" de Rousseau - ou o homem em "estado de natureza" - representa mais que um idílico sonho de retorno ao paraíso original, pois o filósofo enxergava nestes homens primitivos um modelo lógico de crítica ao estado de civilização e ao homem civilizado. O "outro" das terras distantes e desconhecidas era visto com bons olhos por Rousseau, nele o filósofo encontrava um modelo de humanidade, que, na sua visão, definhava junto com a civilização. ${ }^{20}$

Entretanto, entre as noções que constituem o trabalho de Rousseau, a que mais nos interessa neste momento é a de "perfectibilidade", através da qual Rousseau identifica a especificidade propriamente humana, ou seja, aquilo que faz do homem um ser eminentemente humano. A visão de Rousseau é a de que a singularidade humana residia em sua capacidade de sempre superarse, ao contrário dos animais que, ao término de seu processo de maturação, mantêm-se, segundo o filósofo, idênticos por toda sua vida. Assim,

[...] quando as dificuldades que envolvem todas essas questões deixassem algum motivo de discutir sobre essa diferença do homem e do animal, há uma outra qualidade muito específica que os distingue, sobre a qual não pode haver contestação: é a faculdade de se aperfeiçoar, a qual, com o auxílio das circunstâncias, desenvolve sucessivamente todas as outras e reside, entre nós, tanto na espécie como no indivíduo, ao passo que um animal é, no fim de alguns meses, o que será toda a vida, e sua espécie, ao cabo de mil anos, o que era no primeiro desses mil anos. ${ }^{21}$ 
Não encontramos aqui uma noção de evolução contínua e muito menos um sentido teleológico que aponte o "estado de civilização" europeu como sentido único do processo evolutivo, muito pelo contrário, Rousseau não é nada condescendente com o desenvolvimento da experiência civilizatória e a enxerga como um grande equívoco. A "perfectibilidade" humana em Rousseau é a marca de uma humanidade única, ainda que separada em diferentes caminhos mais ou menos afastados do estado de natureza. Ou seja, a "perfectibilidade", origem da especificidade humana é, ao mesmo tempo, o que nos torna homens e o que faz "com que através de séculos desabrochem suas luzes e erros, seus vícios e virtudes, o torna [ao homem] com o tempo tirano de si mesmo e da natureza". ${ }^{22}$

A teoria humanista de Rousseau se tornou um importante paradigma para a composição de um imaginário sobre a diversidade humana durante o século XVIII. Ela construía as bases para pensar na diferença humana dentro de um conjunto lógico de unidade, ou seja, ainda que mais próximos ou afastados do "estado de natureza", a humanidade era um conjunto único. Será, como veremos a frente, com a ruptura desse argumento que surgirão as novas teses evolutivas sobre o desenvolvimento humano. No final, o que estava em jogo era a extensão de alguns dos conceitos que vinham se tornando centrais a partir da Revolução Francesa, tratava-se de se perguntar, "liberdade, igualdade e fraternidade para quem?". O que o filósofo genebrino faz é construir bases para pensar a humanidade enquanto unidade, estabelecendo os alicerces capazes de produzir certa universalização da noção de igualdade. Ao fazer isso, Rousseau inverte a lógica do progresso - tão presente nos filósofos da Ilustração - e, posteriormente, será combatido por teóricos que, ao invés de edenizar o novo mundo e seus habitantes, encontraram no continente e nos homens que o habitam as raízes da decadência e da maldade. É sobre eles que falaremos a seguir.

Nem só de "bons selvagens" viviam os novos continentes e os novos homens que invadiam o imaginário europeu. Uma outra vertente de interpretação da diversidade humana - o leitor deve atentar-se para ela, pois foi a que deixou traços mais profundos na forma de pensar o outro do século XIX - se constitui na substituição da noção de inocência, que encontramos em Rousseau, pelas noções de decadência e maldade inata. É nesse contexto que Buffon, nosso velho conhecido de algumas páginas atrás, apresenta sua tese da "infantilidade do continente". Assim, o naturalista rompe com as noções rousseaunianas e apresenta os novos continentes e seus homens através da noção de carência, ou seja, daquilo que falta aos homens e à toda a natureza o autor chega a citar a quantidade de mosquitos e roedores de pequeno porte como uma das razões que justificam seu argumento. Ainda que defendesse a unidade e a indivisibilidade do gênero humano, Buffon apresenta uma humanidade profundamente hierarquizada, em que os papeis de protagonismo são reservados ao homem europeu. 
Outro autor que assumirá papel importante nesta vertente de pensamento, ainda no século XVIII, será Cornelius de Pauw. O autor insere no debate a noção de degeneração e a utiliza para definir o continente americano. Em sua visão, o continente seria povoado não somente por seres humanos imaturos e "infantilizados", mas sim por seres "decaídos", ou seja, portadores de um "desvio patológico de tipo original". Contudo, mais importante que seu antiamericanismo, que algumas vezes chega a parecer forçado, é a introdução da noção de "degeneração". De Pauw passa a enxergar a humanidade como um grupo heterogêneo e reafirma a primazia das heranças genéticas como elemento indispensável para a constituição do intelecto, da moral e das aptidões do homem.

São estas duas vertentes, a humanista, simbolizada na teoria de Rousseau, e a naturalista - que defendia a diferença inata como raiz da origem dos seres humanos - que conformarão o conjunto do imaginário sobre diferença durante o final do século XVIII e o início do século XIX. A humanidade se verá cingida pela primeira vez e será a busca destas diferentes origens - e a hierarquização delas - que comporão a história do século XIX. É também no início deste século que surge outro conceito que dará apoio aos naturalistas e moldará os debates daqui por diante, estamos falando do conceito de raça, que ganha força com Georges Cuvier e inaugura a noção de heranças físicas permanentes entre os grupos humanos. Os grandes valores das revoluções burguesas - igualdade e liberdade - pareciam agora enfrentar um inimigo à altura. A ideia de raça confinava estes valores a grupos cada vez menores e baseada nela podia-se impor a diferença e a servidão sob o discurso da igualdade e da liberdade. Não reconhecer o outro como um ser cuja origem se aproxima da sua foi, de fato, um passo importante para justificar, sob novas bases - agora mais "científicas" -, as relações de submissão e os imperialismos, com toda as desigualdades advindas destes processos.

No bojo desse debate havia um conjunto de questionamentos muito mais densos e existenciais - ontológicos se quisermos ser fies à denominação com a qual trabalhamos até então. O imaginário social no século XIX será profundamente tocado pelas questões relativas à origem da humanidade. Não será à toa que, neste momento, um grande grupo de relatos sobre "meninos selvagens" tomarão as páginas dos livros e dos jornais. ${ }^{23} \mathrm{O}$ que estava em jogo era, portanto, os limites entre o mundo da natureza e da cultura.

Duas grandes formas de interpretação da origem humana estavam em debate no período, a visão monogenista, que apregoava a unidade da humanidade, surgida de uma fonte comum e origem única; e a visão poligenista - que passará a ser a principal vertente interpretativa nesse momento -, que defendia a existência de vários centros de criação que corresponderiam às diferenças raciais até então observadas. Esta segunda visão ganhará força através da contestação dos dogmas da Igreja e servirá de base para o fortalecimento das 
interpretações que dão às diferenças biológicas papel fundamental na análise dos comportamentos humanos, agora encarados como resultado das leis da biologia e da natureza. Sobre essa concepção afirma Arendt,

[...] a abolição da escravatura nas possessões britânicas em 1834 e a discussão que precedeu a Guerra Civil Americana encontraram na Inglaterra uma opinião pública altamente confusa - solo fértil para as várias doutrinas "naturalistas" que surgiram nessas décadas.

A primeira delas foi representada pelos poligenistas que, acusando a Bíblia de ser um livro de piedosas mentiras, negavam qualquer relação entre as raças humanas; seu principal feito foi a destruição da idéia da lei natural como elo de ligação entre todos os homens e todos os povos. Embora sem estipular uma superioridade racial predestinada, o poligenismo isolou arbitrariamente todos os povos, resultado do profundo abismo gerado pela impossibilidade física da compreensão e comunicação humanas. O poligenismo, ao explicar porque "o Leste é o Leste e o Oeste é o Oeste, e nunca os dois se encontrarão", ajudou a evitar casamentos inter-raciais nas colônias e a promover a discriminação contra indivíduos de origem mista, que, segundo o poligenismo, não são verdadeiros seres humanos, pois não pertencem a raça alguma; ao contrário, cada homem "misto" é uma espécie de monstro porque nele "cada célula é o palco de uma guerra civil" ${ }^{24}$

Seguindo o caminho do argumento de Arendt, podemos dizer que, ao separar, classificar e esquadrinhar o gênero humano, os poligenistas isolaram a humanidade em um diálogo de surdos. Eles retiraram dos "bons selvagens" seus atributos de perfectibilidade e transformaram a dinâmica social em um gradiente de raças no qual a transição de uma tonalidade à outra se transformava em uma aberração. As raças humanas - agora o termo raça ganha primazia transformavam-se, assim, em espécies diferentes e a única forma de redução destas diferenças era a aclimatação ou o cruzamento - não será à toa que ambos encontrarão seus detratores. O leste era o leste e o oeste, o oeste, e nada poderia transformá-los, pois a raiz daquilo que eram estava inscrita em leis da natureza ou, como defendeu a frenologia de Lombroso, nas dimensões dos crânios. ${ }^{25}$

No entanto, é na metade do século que a consolidação de um novo paradigma ganhará forma e será Darwin o responsável por seu estabelecimento, trata-se do paradigma evolutivo. ${ }^{26}$ Poucas teorias dispuseram de impacto tão grande e tão contemporâneo quanto as de Darwin. O abalo causado por suas ideias foi tamanho que, a partir de então, diluíram-se as antigas disputas e 
novos debates se organizaram com base nos conceitos e nas ideias expostas pelo inglês. Com efeito, não era difícil conformar as ideias de diferença inata entre os seres humanos com a terminologia darwinista, o que há de peculiar é que, com os novos conceitos - seleção do mais forte, competição, evolução, hereditariedade -, a noção de raça como distintiva das diferenças humanas sairá dos limites estritamente biológicos e avançará em direção à política $\mathrm{e}$ à cultura. As diferentes apropriações das obras e dos conceitos expostos por Darwin, ou seja, o darwinismo, avança em direção a outros âmbitos distantes da biologia e se torna um modelo para a explicação de toda a sociedade, surge uma geração social-darwinista. ${ }^{27}$

O darwinismo também flertava com outra importante noção do século, a de progresso. Apesar de chegar a uma conclusão oposta àquela originalmente apresentada pelos poligenistas - afinal, em Darwin os homens não só são aparentados entre si, mas também em relação aos animais -, o darwinismo insinua que o gradiente de diferença entre os homens é, na verdade, um gradiente de diferença entre os homens e os animais. A existência de "raças inferiores", que agora são justificadas pela noção de seleção natural, reforça a noção de direito à força, anteriormente justificado em termos tradicionais $\mathrm{e}$ aristocráticos. É novamente Arendt quem nos esclarece sobre a forma com a qual o darwinismo poderia ser utilizado como instrumento de força,

O esmagador sucesso do darwinismo resultou também do fato de ter fornecido, a partir da ideia de hereditariedade, as armas ideológicas para o domínio de uma raça ou de uma classe sobre outra, podendo ser usado tanto a favor como contra a discriminação racial. Do ponto de vista político, o darwinismo era neutro em si: servia como base tanto ao pacifismo e cosmopolitismo, como às formas mais agudas de ideologias imperialistas. ${ }^{28}$

Há, em conjunto com este processo de justificação das diferenças, uma restrição à antiga noção de perfectibilidade, antes atributo distintivo da humanidade, agora ela será de posse apenas das "raças civilizadas", únicas capazes de alcançar o estágio civilizatório. Em conjunto com a ideia de progresso e de evolução - em conjunto à oposição civilização vs Barbárie -, traça-se um sentido teleológico de finalidade do processo evolutivo, cujo ápice será sempre a civilização de modelo europeu.

Quando tecemos comentários sobre as relações entre humanidade e animalidade, entre cultura e natureza, não estamos somente tecendo considerações filosóficas ou colocando em cheque a forma com a qual a ontologia presente na cultura ocidental - e também na ciência - vê o mundo. De fato, a identificação é um esforço que se produz em conjunto a uma tomada de posição em relação à experiência individual e coletiva. Ou seja, a identificação 
a determinado elemento na diversidade permite a autodefinição em relação a outros seres e dá justificativas para as relações, alteritária ou não, que se darão neste contato. Ao identificar semelhanças e diferenças com o outro, ao hierarquiza-las com relação a um conjunto de regras previamente marcadas, o que estamos fazendo é nos definir no mundo - é essa definição que tentamos resgatar ao mergulhar nos jogos de teorias que compunham o imaginário social no século XIX. A raiz de todo o processo relacional se dá, assim, na identificação - ou não - com o outro, identificação esta que, algumas vezes, é surpreendentemente a razão de todas as distinções e conflitos.

Transforma-se, assim, a antiga noção de desigualdade entre os homens, que residia na constatação da diversidade contingente de traços, em diferença, que passa a denotar dessemelhanças profundas e irreparáveis. No trem da história - que, segundo Walter Benjamin, avança em direção ao abismo - só eram distribuídos alguns bilhetes de acesso à humanidade, enquanto a outros, impedidos de embarcar, restava ocupar qualquer lugar na estação, entre o homem e o animal. ${ }^{29}$

\section{Notas}

1 THOMPSON, E.P. A miséria da teoria ou um planetário de erros: uma crítica ao pensamento de Althusser. Rio de Janeiro: Zahar, 1981. p. 111.

2 Alguns antropólogos afirmam mesmo ser o animismo uma forma de ontologia do totemismo, outra relação bastante presente nos grupos nativos americanos. Cf. CEMIN, Arneide. de. Xamanismo: Algumas abordagens teóricas. In: Revista de educação, cultura e meio ambiente Março $\mathrm{N}^{\circ}$ 15, V. 3, 1999. Disponível.em: <.http://www.revistapresenca. unir.br/artigos_presenca/15arneidecemin_xamanismo.pdf/> Acessado em 11 Ago. 2014; CASTRO, Eduardo Viveiros de. Os pronomes cosmológicos e o perspectivismo ameríndio. In: Mana [online]. 1996, vol.2, n.2, pp. 115-144; PARDINI, Patrick. Natureza e cultura na paisagem amazônica: uma experiência fotográfica com ressonâncias na cosmologia ameríndia e na ecologia histórica. In: Boletim do Museu Paraense Emílio Goeldi de Ciências Humanas, Belém, v.7, n.2, ago. 2012. Disponível em </http://www.scielo.br/scielo.php?script $=$ sci_arttext\&pid $=$ S1981-81222012000200017\&lng=pt\&nrm=isso $>$. Acesso em 14 dez. 2014.

3 Cf. DESCOLA, Phillipe. Par de-là nature et culture. Paris : Gallimard, 2005. p. 183.

4 Lévi-Strauss, Claude. O cru e o cozido: Mitológicas I. São Paulo: Cosac Naify, 2004. p.38.

5"A natureza e as leis da natureza estavam imersas em trevas; Deus disse "haja Newton" e tudo se iluminou." (Tradução nossa.)

6 Esforço semelhante também estava presente nas classificações da "Historia Animallum" de Aristóteles.

7 "No século XVIII, a continuidade da natureza é exigida por toda história natural, isto é, por todo esforço para instaurar na natureza uma ordem e nela descobrir categorias gerais, quer sejam elas reais e prescritas por distinções manifestas, quer cômoda e simplesmente 
demarcadas por nossa imaginação. Só o contínuo pode garantir que a natureza se repita e que a estrutura, por consequência, possa tornar-se caráter.” FOUCAULT, Michel. Les mots et les choses: Une archéologie des sciences humaines. Paris : Gallimard, 1966. p. 121.

8 Georges-Louis Leclerc, o Conde de Buffon foi um dos primeiros biólogos a sugerir que a origem dos animais deveria ser resultante dos próprios animais. O próprio Darwin apontaria Buffon como um dos percussores do estudo científico das espécies.

9 “A alma, o pensamento, a palavra, não dependem portanto da forma ou da organização do corpo; nada prova melhor que este é um dom particular ao homem, uma vez que o orangotango, que não fala nem pensa, tem, no entanto, o corpo, os membros, os sentidos, o cérebro e a língua inteiramente semelhantes ao homem; Ainda que ele possa fazer ou imitar todos os movimentos, todas as ações humanas, no entanto, ele não faz nenhum ato humano." (Tradução Nossa.) RICHARD, A. Oeuvres complètes de Buffon, mises en ordre et précédées d'une notice historique. Paris : Raudouin Frères Editeurs, 1928. p. 587.

10 "No ano de 1647, um tenente da marinha sueca de nome Nicolas Köping estava servindo a bordo de um navio mercante holandês na baía de Bengala. Um dia o navio aproximou-se de uma ilha onde seus habitantes nus, de acordo com o relato de Köping, tinham caudas como aquelas dos gatos, e um comportamento similar ao dos felinos. Aproximando-se em suas canoas, estes nativos - evidentemente inclinados à troca - ameaçaram invadir o barco e tiveram de ser assustados com tiros de canhão. O piloto do navio subsequentemente designou um grupo de cinco marinheiros para vasculhar a ilha em busca de provisões. Eles nunca retornaram, e uma busca montada na manhã seguinte revelou seus ossos descartados ao lado de uma fogueira ainda fumegante além de seu barco, do qual tinham sido removidas sistematicamente todas as cavilhas de ferro." (Tradução Nossa). INGOLD, Tim. (ed.), Companion Encyclopedia of Anthropology, Londres: Routledge, 1994. p. 15.

11 A atuação de Linné no campo da zoologia e da botânica, além de seu esforço na produção de obras classificatórias, lhe deram o título de "pai da taxonomia moderna". Goethe, o proeminente autor alemão, chegou a declarar que "Com a exceção de Shakespeare e Spinoza, eu não conheço outro ser que tenha me influenciado mais profundamente."

12 HOPPIUS, C.E. Amoenitates academicae. Erlangen: Holmice \& Lipsice, 1760.

13 “Eu me sensibilizo, no entanto, que aqueles que acreditam que os homens são, e sempre foram, os mesmos em todas as épocas e nações do mundo, tal como os vemos na Europa, pensarão que esta história é realmente incrível; mas, de minha parte, eu estou convencido que nós não descobrimos ainda toda a variedade da natureza, não mesmo em nossa própria espécie; e a coisa mais incrível, na minha apreensão, que pode ser dita, ainda que não houvesse fatos que a contradizem, seria que todos os homens em diferentes partes da terra foram os mesmos em tamanho, aparência, forma cor." (Tradução nossa.) MONBODDO, James Burnett. Of the origin and progress of language. 6 vols. Edinburgh, 1786. Vol I. p. 261.

14 London Sketch Book of Celebrities "Prof. Darwin. This is the ape of form," 18 de fevereiro de 1874.

15 La Petite Lune. n.10. 23 de Agosto de 1878.

16 HUNT, Lynn. A invenção dos direitos humanos, uma história. São Paulo: Cia das Letras, 2009.

17 Obra fundamental para a compreensão das transformações no imaginário social europeu e sua relação com o descobrimento da américa é a de HOLLANDA, Sergio Buarque de. Visão do Paraíso: os motivos edênicos no descobrimento e colonização do Brasil. São Paulo: Cia das Letras, 2010. 
18 MELLO E SOUZA, Laura de. O diabo e a Terra de Santa Cruz: feitiçaria e religiosidade popular no Brasil colonial. São Paulo: Cia das Letras, 1986. p. 24.

19 CLASTRES, Hélène. Primitivismo e ciência do homem no século XVIII. In: Discurso 13. São Paulo: Polis. p. 190-191.

20 Em uma das notas de seu "discurso sobre a origem da desigualdade entre os homens", Rousseau chega a afirmar que, "Seu saber e sua indústria se limitam a saltar, correr, bater-se, lançar uma pedra, subir em uma árvore. Mas, se só sabe essas coisas, em compensação as sabe muito melhor do que nós, que não temos a mesma necessidade dela que ele. E, como dependem unicamente do exercício do corpo, não sendo suscetíveis de nenhuma comunicação nem de nenhum progresso de um indivíduo para outro, o primeiro homem pode ser nisso tão hábil quanto os seus descendentes. As narrativas dos viajantes estão cheias de exemplos da força e do vigor dos homens nas nações bárbaras e selvagens; não gabam menos sua destreza e agilidade; e, como basta ter olhos para observar essas coisas, nada impede que nos mereça fé o que é certificado por testemunhas oculares." Cf. ROUSSEAU, Jean Jacques. Discurso sobre a origem da desigualdade entre os homens. In: Coleção Os pensadores. São Paulo: Abril Cultural, 1973. p.49.

21 Ibidem, p. 18.

22 Idem.

23 Um bom exemplo são os livros escritos pelo psiquiatra francês Jean Itard, "De l'education d'un homme sauvage ou des premiers developpemens physiques et moraux du jeune sauvage de l'Aveyron" (1801) e "Rapports et memoires sur le sauvage de l'Aveyron" (1807). A história de Itard com as crianças selvagens foi transformada em filme pelo genial diretor François Truffaut em "L'enfant Sauvage" (1970).

24 ARENDT, Hannah. As origens do totalitarismo. São Paulo: Cia das letras, 2000. p. 193.

25 A frenologia, ou seja, o estudo das dimensões cranianas como elemento de relação entre a exterioridade física e características mentais serviu de inspiração a diversas caricaturas que, ainda que com objetivos totalmente diversos e derrisórios, buscavam algo semelhante, representar o caráter através das distorções da forma.

26 Estamos nos utilizando aqui da noção de paradigma conforme Kuhn. Cf. KUHN, Thomas. A estrutura das revoluções científicas. São Paulo: Perspectiva, 1970. p. 13.

27 Sobre o impacto das teorias de Darwin na conformação daquilo que chamamos de Darwinismo social, ver: HOFSTADTER, Richard. Social darwinism in american thought. Boston: Beacon Press, 1955.

28 ARENDT, Hannah. Op. Cit. p. 207.

29 BENJAMIN, Walter. Obras escolhidas: Magia e técnica, arte e política: ensaios sobre literatura e história da cultura. São Paulo: Brasiliense, 2012. p. 241.

Recebido em 02/07/2016

Aprovado em 13/09/207 